\title{
Exploration of National Quality course for Agricultural Mechanics
}

\author{
Geng Duanyang ${ }^{1, \mathrm{a}}$, Zhang Daolin $^{1, \mathrm{~b}}, \mathrm{Jiang}$ Chunyan ${ }^{1, \mathrm{c}}$, Meng Pengxiang $^{1, \mathrm{~d}}$ \\ ${ }^{1}$ School of Agricultural and food school Shandong university of technology,Zibo,Shandong, China \\ adygxt@163.com, bzbzdl@sdut.edu.cn, 695482655@qq.com, ${ }^{\mathrm{d}}$ mengfanmu8@163.com
}

Keywords: Quality curriculum, plan,construction,undergraduate, University Education.

Abstract. Combined with the construction of agricultural mechanics of quality curriculum in Shandong university of technology, The plan for improving the quality curriculum standard was established by analyzing content plan, teaching module, testing and assessing system, and timely update system of this course, which laid a foundation for a high level of quality curriculum.

\section{Introduction}

The education engineering of quality course was formally launched in China while the notice of booting the teaching quality of university education and teaching innovation engineering which was published by education ministry in April 8, 2003. The education engineering mainly constructs a network platform to make the quality resources popularity by sharing the internet resource, which may provide a convenience platform to self-study and self-test at any time or anywhere for college students, technical personnel and other learners, Obviously, it is very important to construct a high quality and efficient knowledge learning platform for achieving the goal [1,2].

\section{To plan the quality course content}

The quality course is a way of knowledge dissemination in information times, which may supply the necessary knowledge of self-learning, reference and self-test for all studying personnel. It must include all the required information and data to learners, which includes the teaching team modules displayed teaching level, the course content module highlighted key content teaching course, self-testing and evaluating module for the studying effect of learners and

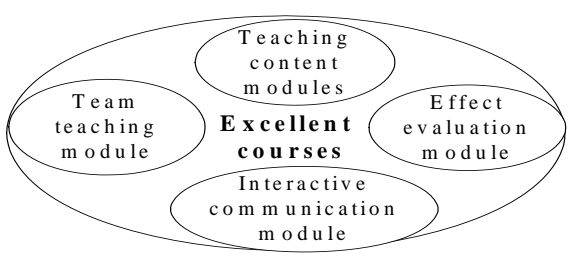

Fig.1 Course content planning interactive communication module used for exchanging information between learners and learners or learners and teachers, as shown in figure 1.and the following modules of teaching, interactive communication and expressing achievement are the key factors for learners to achieve the teaching goal .

\section{Teaching content module}

Teaching contents are the expression of subject knowledge system and the core of learning. So it must be highly refined and scientifically expressed according to the teaching time schedule and teaching goal. The teaching content module was established as figure 2 which was reasoned layer by layer based on above goal. Both the theory study and practical part were emphasized in this module.

\section{A. To study the theory knowledge}

As shown in Figure 2, the theoretical knowledge was mainly studied by classroom teaching which included textbook content. For example, the key content of agricultural mechanics included the functions, compositions, performance parameters and characteristics of motion of key components of agricultural machine and so on[3]. With the deepening of the teaching reform at the time of current knowledge explosion, the teaching time of each course is shortened, the contents of this course were divided into basic knowledge, deepening knowledge, extracurricular enhance knowledge and 


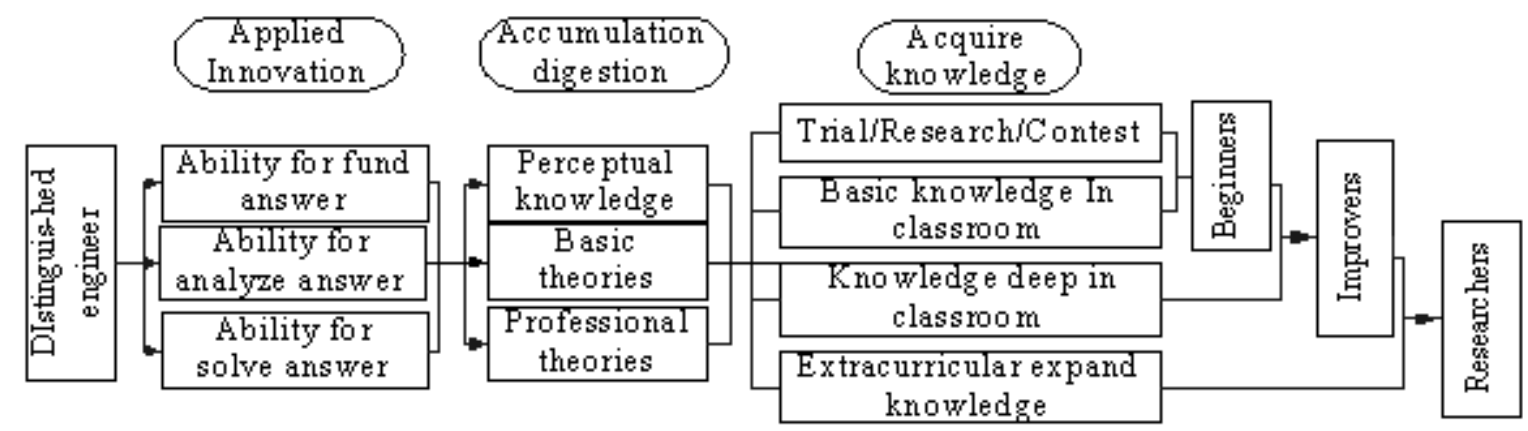

Fig.2 Determination on fundamental content

experimental knowledge which was based on the limit teaching time and different learners[4]. For example, the basic knowledge was first introduced which included technical requirements, part functions, seeder types and its development trend during teaching process of the seeder section, which might form an overall concept for learners. Then the teaching content was deepened including the determination of main technical parameters and the motion law of seeder key parts and so on, which may teach students to master the analyzing and designing method of general machine or equipment, and the foundation was set for extracurricular enhance ability. At last, in order to improve the knowledge application ability, some extra extracurricular exercise must be supplied. [5].

\section{B. To obtain practical knowledge}

The students have been used to classroom teaching for a long time. But they were required to own some practical ability by many corporations in recent years. For example, the corporation clearly asked students to own some work experience and took part in some social exercises. So the following practical activities were strengthened during studying process of this course.

- To supply classroom knowledge and deepen the teaching practice content. Many performance experiments, structural recognition activities, operating experiments and others were introduced.

- To develop some simulated designs of the agricultural equipment properly. Due to the limitation of the teaching time, the students were divided in to groups to design some key parts of agricultural machines including the drainage digger of southern seeder, potato seeder meter and other devices.

- To make full use of the practice base outside school and program practice contents. Since the production tasks of modern corporations were relatively heavy, the pipeline operations were used in many corporations in order to catch up with the progress of production and reduce the cost. The students must be strengthened to guide during the practical activities in order to avoid being busy with the production activity in such social practical activities. For example, the students were asked to understand the working principle, production process, material select method, structural features and so on from the practical activities, and the studying effect was increasingly improved.

- To encourage students to participate the electrical and mechanical competition. Achievement is the vane and the power source of studying. It is the effective way of gaining achievements to attend such related matches. In order to make students to study actively, the students were often asked to find, analyze and solve the problems by themselves under the guidance of teachers, and even encouraged them to make some progress by their effort. After several years of development, these students participated the related competitions were often found to own higher abilities of design and innovation than common students [6].

\section{C.To evaluate and test the studying effect}

The examination was not the sole purpose, it could evaluate studying effect, indicate the direction of studying for learners and reveal the existing problems so that they could realize the gap and make up for the deficiency of study as soon as possible. The

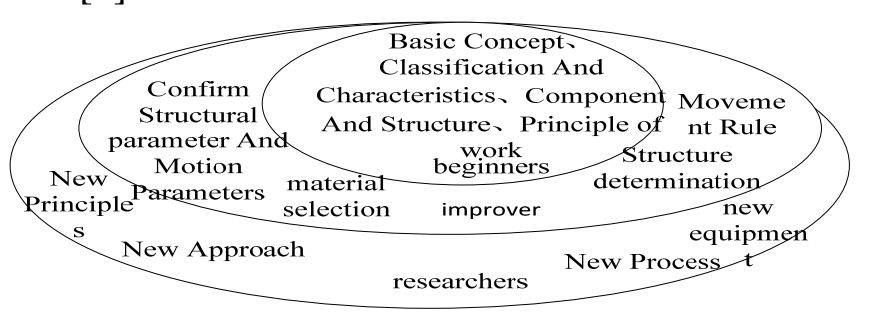

Fig.3 Test requirements 
evaluating and test system of quality course was different from the general test, which stressed to carry out different exam standards for different level learners. In this system, the learners were divided into three grades - beginner, improver and expert according to the above research. The beginners focused on the evaluation of agricultural machinery composition, function, agronomic requirements etc; Based on mastering the content of beginners, the improvers focused on the analysis of structure design, parameter establishment of the key components; based on above all, the experts should emphasize on the ability test of using their theory to solve the actual questions, which could improve their innovative, and achieve the purpose of live learning, just as shown in figure 3.

\section{To dynamically update and guarantee the study effect}

First, the quality curriculum is a model course which has some characteristics such as first-class teachers, teaching contents, methods and teaching management [7]. But the knowledge owns timeliness character, in order to ensure the progressiveness and frontier of teaching content, the teachers must timely update their teaching contents which not only include electronic documents for teaching, but also include some video materials and others.

Secondly, because quality course are opened not only to the students in our school, but also other students and technical personnel of enterprises, they might meet difficulties and problems in the studying process at any time. In fact, according to teaching experience by our teaching team, some students who were willing to actively study often solved such problems through looking up the related information and studying by themselves. But many students felt very confused for the passive studying students. It is obvious that it is not helpful for solving problems and raising the students' abilities. Therefore a interactive platform was supported in the quality agricultural mechanics. On the one hand, such communicating way could remove the gap between teachers and students, and was favor for knowing the teaching effect in time; on the other hand, the teacher could get some living teaching source materials by answering the questions asked by technical personnel in line, which could be timely added into the teaching content to make students understand the practicability of studying subject knowledge, furthermore, could stimulate their studying interest, and improve students' learning initiative and enthusiasm.

Finally, as the college entrance examination is a studying baton for middle school students, the examination module and exercise in quality curriculum also is a navigation mark for most students. So many test content and exercise such as practical questions which were met by enterprise technical persons must be supplied to encourage students to find, analyze and solve the questions which may finally improve their practical abilities. For example how to accurately seed the grain in the no-tillage fields, and how to solve the problem of inconsistent between agricultural machinery and agronomy for corn harvesting process and so on were supplied in time, and the students were guided to consider and analyze, which could not only make students to know the developing trends of agricultural machinery, and to know the hot issues which were cared by the enterprises.

\section{To express the achievement}

In the era of knowledge explosion, each quality course was built by $2 \sim 3$ universities. How to make the learners to choose, accept and approval the studying content by our university? All of the achievements which were obtained by our teaching team and students, and even including the character of this course, research and experimental conditions, and some video materials which may broad the vision of the learners[8].

The student's achievements are the key role to attract students in our university. It is difficult to compare with strength and level objectively because it was influenced by different teaching environment, teaching object, teaching process and others for different levels universities. So the students might lose their study confidence if comparison was blindly made, which was not conducive to cultivate students to be a innovative talents. But for the achievement obtained by students in our 
university, it owns strong call and excitation for students in our university because it can be achieved by their efforts.

The research achievement of teaching team was the mark of strength of the teaching team. And the relationship between teaching and research is closely associated, the teaching will be very boring and dull without supported by research achievement, and the level of research will be difficult to raise without teaching theory, so if the teaching theory is combined with research work, the teaching theory will be validated by practical research activity, which may prevent researchers from a detour route. As a same reason, the science research may be provided by many living, actual examples, which may increase the class interesting. In a word, their relationship is closely associated by each other; secondly, the team achievement can arouse students' more attention, strengthen team cohesion, establish team's image and enhance team influence, which may point effect direction and enhance study power for learners.

\section{Conclusions}

By the above analysis, the construction of following aspects must be strengthened for building a first-class quality course:

- To strengthen the construct of the curriculum contents and pay attention to the form of knowledge expression.

- To strengthen the guidance of the testing and evaluating system and stimulate the enthusiasm of the students.

- To dynamically update course contents to guarantee timeliness and frontier of teaching content.

- To raise the level of achievement so as to expand the influence of quality curriculum.

Besides above all, it is important for quality course construction to work hard by teaching team, to participate actively by more and more learners, which may improve the overall strength, enrich the content of quality course, and finally cultivate more and more creative talents for our country.

\section{References}

[1] Li Yinghui, Liu Juan. The" management of travel agency" research on the construction of excellent course. Journal of Changsha University. Vol.25(3):139-141(2011).

[2] Fan Chuanhong. The construction of excellent course of ideological and political theory class. Journal of Northeast Agricultural University. Vol.2:117-119(2011).

[3] Zhao Yuee. Excellent course's teaching method discussion of" mechanical drawing". Value Engineering. Vol.30(16):199-199(2011).

[4] Li Ling. Teaching design of excellent courses construction in university. New curriculum learning: academic education. Vol.3:65-66(2011).

[5] Jin Dan, Meng Fanping, Cui Fengde, etc. Make excellent curriculum construction as the platform, improving cultivation quality of the innovation talents. Journal of Medical Science Yanbian University. Vol.34(1):64-65(2011).

[6] Song Hailong, Tuo qing, Zhang Shuzhen. Based on the construction of the project management of the excellent curriculum - Taking Ji shou University as an example. Higher Education of Sciences. Vol.2:83-86(2011).

[7] Yang Liyuan. Promote teaching reform by research and create the high quality curriculum actively. Journal of Tangshan College.Vol.24(2):97-99(2011).

[8] Liu Siwei. As the core of improve the quality and outstanding characteristics that constructed good excellent course of "trade economics". Journal of Hunan Business College.Vol.18(2): 63-68(2011). 